Research Article

\title{
Plasma Treated Active Carbon for Capacitive Deionization of Saline Water
}

\author{
Aiping Zeng, ${ }^{1,2}$ Maheshwar Shrestha, ${ }^{2}$ Keliang Wang, ${ }^{2}$ Victor F. Neto, ${ }^{1}$ \\ Bárbara Gabriel, ${ }^{1}$ and Qi Hua Fan² \\ ${ }^{1}$ Centre for Mechanical Technology and Automation, Department of Mechanical Engineering, University of Aveiro, \\ 3810-193 Aveiro, Portugal \\ ${ }^{2}$ Department of Electrical and Computer Engineering and Department of Chemical Engineering and Materials Science, \\ Michigan State University, East Lansing, MI 48824, USA
}

Correspondence should be addressed to Aiping Zeng; aiping.zeng@ua.pt and Qi Hua Fan; qfan@egr.msu.edu

Received 23 February 2017; Revised 9 May 2017; Accepted 28 May 2017; Published 19 July 2017

Academic Editor: Flavio Colmati

Copyright (c) 2017 Aiping Zeng et al. This is an open access article distributed under the Creative Commons Attribution License, which permits unrestricted use, distribution, and reproduction in any medium, provided the original work is properly cited.

\begin{abstract}
The plasma treatment on commercial active carbon (AC) was carried out in a capacitively coupled plasma system using Ar $+10 \%$ $\mathrm{O}_{2}$ at pressure of 4.0 Torr. The RF plasma power ranged from $50 \mathrm{~W}$ to $100 \mathrm{~W}$ and the processing time was $10 \mathrm{~min}$. The carbon film electrode was fabricated by electrophoretic deposition. Micro-Raman spectroscopy revealed the highly increased disorder of $\mathrm{sp}^{2} \mathrm{C}$ lattice for the AC treated at $75 \mathrm{~W}$. An electrosorption capacity of $6.15 \mathrm{mg} / \mathrm{g}$ was recorded for the carbon treated at $75 \mathrm{~W}$ in a $0.1 \mathrm{mM}$ $\mathrm{NaCl}$ solution when $1.5 \mathrm{~V}$ was applied for 5 hours, while the capacity of the untreated AC was $1.01 \mathrm{mg} / \mathrm{g}$. The plasma treatment led to 5.09 times increase in the absorption capacity. The jump of electrosorption capacity by plasma treatment was consistent with the Raman spectra and electrochemical double layer capacitance. This work demonstrated that plasma treatment was a potentially efficient approach to activating biochar to serve as electrode material for capacitive deionization (CDI).
\end{abstract}

\section{Introduction}

With increasing worldwide demands for fresh water, brackish water is considered a potential source especially in those areas with limited renewable water resources [1-3]. Capacitive deionization (CDI), also known as electrosorption, is an emerging water desalination method capable of competing with current membrane- and distillation-based mainstream technologies [1-3]. The principle of CDI is based on imposing an external electrostatic field to force the charged ions to move toward the opposite electrodes. The charged ions can be attracted within the electrical double layer formed between the solution and electrode interface. CDI has attracted enormous attention in recent years as an energy saving and environmentally friendly desalination technique, because it can be conducted at ambient conditions and low voltages $(<2 \mathrm{~V})$ without secondary waste and does not require high-pressure pumps, membranes, distillation columns, or thermal heaters [3-9]. It is well known that the ion adsorption capacity of an electrode is directly related to its surface area and bulk conductivity. Hence, porous carbon materials with high surface area and good conductivity, such as active carbon (AC) [10-13], carbon aerogels $[14,15]$, carbon nanofiber $[16,17]$, carbon nanotubes $[18,19]$, and mesoporous carbon $[20,21]$ have been widely used as the CDI electrodes.

Cost considerations are of key importance to making CDI an affordable mass-production technology. AC from abundant natural sources is currently considered the most promising material for the CDI electrodes; however, the electrosorption of commercial ACs is limited. Secondary activation is being developed to improve their performance. Of them, the $\mathrm{KOH}$ activation has been successively developed for using ACs for electrochemical supercapacitors which shares the same electrochemical double layer theory with electrosorption. The $\mathrm{KOH}$ activation process is energy intensive ( $\sim 850-960^{\circ} \mathrm{C}$ for a couple of hours) with serious environmental concerns due to the use of $\mathrm{KOH}[22,23]$. Therefore, activating biocarbon has become a critical barrier 


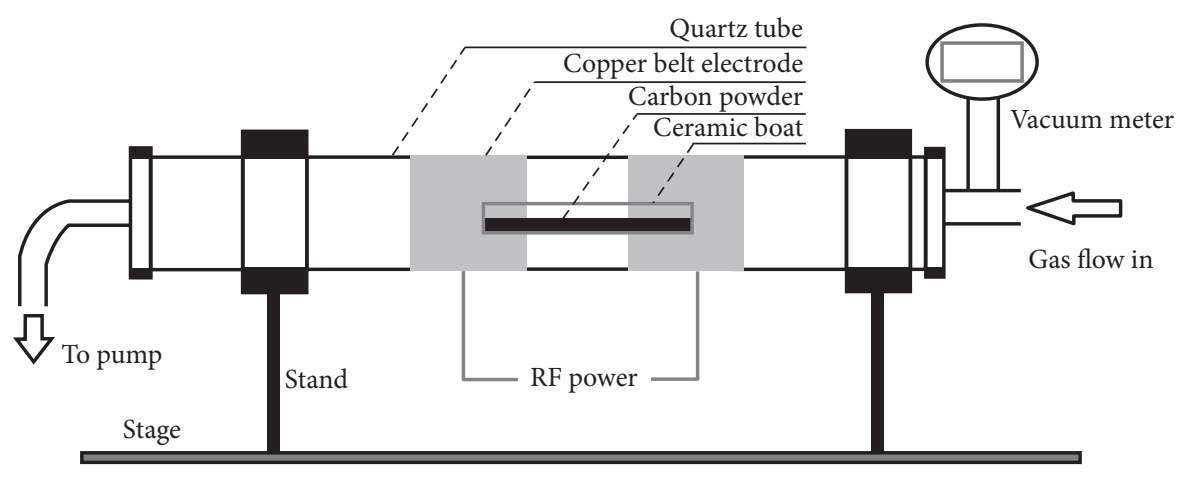

FIGURE 1: Schematic of the capacitively coupled RF plasma system (not in scale).

to commercializing AC for CDI. This work first demonstrates that capacitively coupled RF plasma is a potentially efficient approach to activating biochar.

\section{Materials and Experimental}

2.1. Materials and Plasma Process. Commercial AC powder YP-50F (Kuraray Chemical Co., Ltd), which was activated by steam, was used in this work. The plasma process was carried out in a custom-made capacitively coupled plasma system at South Dakota State University. The schematic of plasma system is presented in Figure 1. A quartz tube with inner diameter of $4.8 \mathrm{~cm}$ was taken as vacuum chamber which was pumped by a mechanical pump. Two copper belts of $5 \mathrm{~cm}$ width were attached to the outside of the tube to serve as coupled electrodes. The distance between the two electrodes was $10 \mathrm{~cm}$. The two electrodes were connected to RF power (Kurt J. Lesker, Radio Frequency Power Supply R301) to generate plasma. The AC powder of $0.27 \mathrm{~g}$ was spread at the bottom of a ceramic boat (inside $9.5 \mathrm{~cm} \times 3.4 \mathrm{~cm} \times 1.5 \mathrm{~cm}$ height) which was put between the two electrodes. The tube was pumped down to 0.5 Torr as basic vacuum. Mixed gas of $\mathrm{Ar}+10 \% \mathrm{O}_{2}$ at purity of $99.99 \%$ was used as the plasma environment and the pressure was kept at 4.0 Torr (measured by vacuum meter, Kurt J. Lesker, Model: KJL275806) during the plasma process. The power of plasma ranged from $50 \mathrm{~W}$ to $100 \mathrm{~W}$ and the process time was $10 \mathrm{~min}$.

2.2. Carbon Electrode Fabrication. The AC electrode film was fabricated by electrophoretic deposition on graphite current collector (Ohio Carbon Blank, EDM Grade, $1.0 \mathrm{~mm}$ thickness). The AC suspension solution was made of $0.25 \mathrm{~g}$ YP-50F $+0.025 \mathrm{~g}$ ethyl cellulose (Sigma-Aldrich) $+0.025 \mathrm{~g}$ acetylene black (Kuraray Chemical Co., Ltd) $+75 \mathrm{ml}$ Isopropanol (Fisher Chemical, Histological Grade). In order to get even carbon powder suspension, the solution was sonicated for 2 hours and kept stirring for $>6$ hours before deposition. In the deposition process, the distance of the two electrodes was $5 \mathrm{~mm}$, and the carbon powder was deposited to the positive electrode with voltage of $80 \mathrm{~V}$ DC. The deposited carbon film was baked at $60^{\circ} \mathrm{C}$ in an oven for 12 hours before it was tested.

2.3. Electrochemical and Electrosorption Measurements. The electrochemical response of the AC electrodes was measured

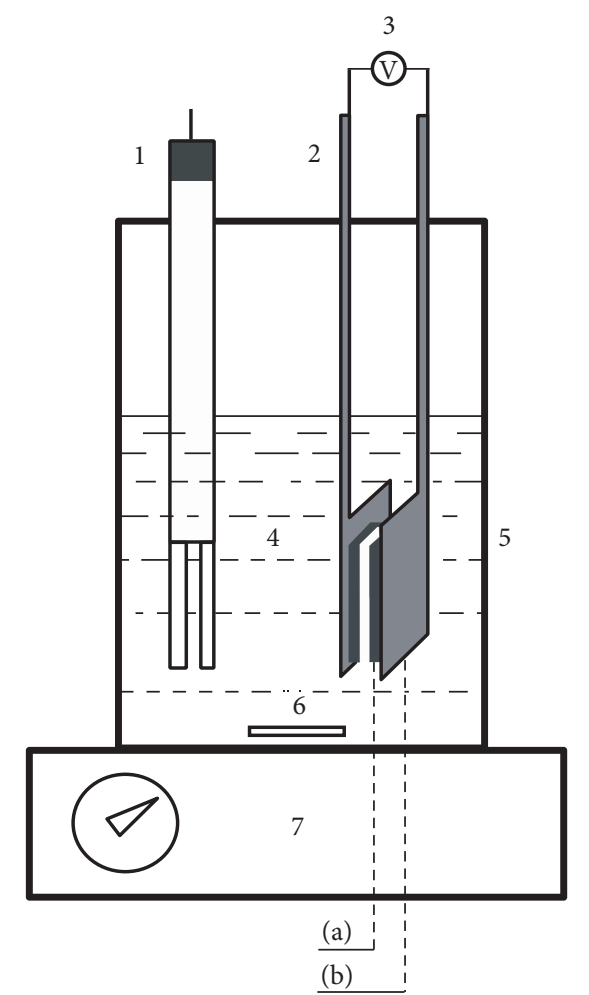

FIGURE 2: Schematic of the electrosorption set-up (not in scale): (1) conductivity meter, (2) active carbon electrode ((a) carbon film and (b) current collector), (3) potentiostat, (4) saline solution, (5) glass cylinder, (6) stirrer bar, and (7) magnetic stirrer stage.

on a conventional three-electrode cell. A Princeton Applied Research Potentiostat (VersaStat 3 with VersaStudio software) was used. The AC working electrode was sealed by $\mathrm{O}$ ring with an exposed diameter of $8.1 \mathrm{~mm}$. The other two electrodes were an $\mathrm{Ag}$ count electrode and an $\mathrm{Ag} / \mathrm{AgCl}$ reference electrode in saturated $\mathrm{KCl}$ aqueous solution. The testing solution was $0.5 \mathrm{M} \mathrm{NaCl}$ with volume of $2.5 \mathrm{ml}$. The AC film density was 1.91 to $5.85 \mathrm{~g} / \mathrm{m}^{2}$.

The electrosorption experiments were performed in a cylindrical cell assembled with a pair of active carbon electrodes. The schematic of CDI set-up is shown in Figure 2. 
TABLE 1: Analyzed EDS results and contact angle of untreated active carbon and active carbon treated at different plasma powers: $50 \mathrm{~W}, 75 \mathrm{~W}$, and $100 \mathrm{~W}$ (EDS conditions: $10.0 \mathrm{kV}$; takeoff angle: $35.0^{\circ}$; elapsed live-time 10.0 ).

\begin{tabular}{|c|c|c|c|c|c|c|}
\hline \multicolumn{6}{|c|}{ EDX analysis } & \multirow{2}{*}{ Contact angle $\left({ }^{\circ} \mathrm{c}\right)$} \\
\hline & Element & Line & Intensity $(\mathrm{c} / \mathrm{s})$ & Error, 2-sig & Concentration (wt\%) & \\
\hline \multirow{3}{*}{ Untreated } & $\mathrm{C}$ & $\mathrm{Ka}$ & 657.85 & 16.221 & 96.347 & \multirow{3}{*}{130} \\
\hline & $\mathrm{O}$ & $\mathrm{Ka}$ & 5.73 & 1.513 & 3.653 & \\
\hline & Total & - & - & - & 100.000 & \\
\hline \multirow{3}{*}{$50 \mathrm{~W}$} & $\mathrm{C}$ & $\mathrm{Ka}$ & 769.58 & 17.545 & 93.724 & \multirow{3}{*}{107} \\
\hline & $\mathrm{O}$ & $\mathrm{Ka}$ & 12.33 & 2.220 & 6.276 & \\
\hline & Total & - & - & - & 100.000 & \\
\hline \multirow{3}{*}{$75 \mathrm{~W}$} & $\mathrm{C}$ & $\mathrm{Ka}$ & 533.37 & 14.606 & 93.333 & \multirow{3}{*}{105.5} \\
\hline & $\mathrm{O}$ & $\mathrm{Ka}$ & 9.17 & 1.915 & 6.667 & \\
\hline & Total & - & - & - & 100.000 & \\
\hline \multirow{3}{*}{$100 \mathrm{~W}$} & $\mathrm{C}$ & $\mathrm{Ka}$ & 538.19 & 14.672 & 93.137 & \multirow{3}{*}{102.5} \\
\hline & $\mathrm{O}$ & $\mathrm{Ka}$ & 9.57 & 1.957 & 6.863 & \\
\hline & Total & - & - & - & 100.000 & \\
\hline
\end{tabular}

Every electrode was coated with AC with area of $25 \mathrm{~mm}$ $\times 19 \mathrm{~mm}$ immersed in solution. In order to measure the electrosorption capacity of AC precisely, the carbon film used for the electrosorption was thicker than for the investigation of electrochemical response, and the density of active carbon was 21.05 to $105.26 \mathrm{~g} / \mathrm{m}^{2}$. The gap between the two electrodes was $5 \mathrm{~mm}$. An external potential of $1.5 \mathrm{~V}$ was applied on the electrode pairs for 5 hours and then was removed. The solution concentration was $0.1 \mathrm{mM} \mathrm{NaCl}$ with volume of $50 \mathrm{ml}$. The solution was kept stirring with magnetic bar and deairing with Ar gas bubbling. Its electrical conductivity was monitored with conductivity meter (Mettler Toledo).

The electrosorption capacity $(M)$ was calculated as the mass of adsorbed salt per gram mass of the AC on the electrodes $(\mathrm{mg} / \mathrm{g})$ using the following equation:

$$
M=\left[\left(C_{0}-C\right) * \frac{V}{m}\right] * M_{\mathrm{NaCl}} * 1000,
$$

where $C_{0}$ is the initial molar concentration of salt solution $(\mathrm{mol} / \mathrm{L}), C$ is the concentration after adsorption $(\mathrm{mol} / \mathrm{L})$, $V$ is the volume of solution (L) and $m$ is the mass of the active carbon ( $\mathrm{g}$ ), and $M_{\mathrm{NaCl}}$ is the molar mass of $\mathrm{NaCl}$ (g/molar). $C$ and $C_{0}$ values were calculated from a calibration pattern considering the conductivity of the $\mathrm{NaCl}$ solutions with known concentrations.

\subsection{Material Characterization and Contact Angle Measure-} ment. The AC material structure before and after plasma treatment was characterized by a micro-Raman spectroscope (Horiba Jobin Yvon, Laser at $532 \mathrm{~nm}$ ) examining the respective carbon electrodes. The electrode material morphology and composite were investigated using a scanning electron microscope (HITACHI S-3400N) with energy dispersive Xray analysis (EDX). Contact angle measurements were also carried out on the carbon electrode surface using deionized water with drop of $5 \mu \mathrm{L}$. A Krüss drop shape analysis system DSA $10 \mathrm{Mk} 2$ was employed to perform the measurement.

\section{Results and Discussion}

3.1. Micromorphology and Raman Spectra. Figure 3 shows the SEM images of the AC electrodes before and after plasma treatment at power of $100 \mathrm{~W}$. The carbon electrodes treated at other plasma powers have similar morphology to the one treated at $100 \mathrm{~W}$, but less fine powder with decreased plasma power. It was found that the plasma treatment broke the carbon particles into powders smaller than $1.0 \mu \mathrm{m}$. EDX (Figure 4 and Table 1) showed that the plasma treatment significantly increased the oxygen content from $3.65 \mathrm{wt} \%$ to $6.27 \mathrm{wt} \%$ for the carbon treated at power of $50 \mathrm{~W}$ and but the oxygen content slightly increased with the plasma power from $50 \mathrm{~W}$ to $100 \mathrm{~W}$. C-O groups can decrease carbon material surface energy. It was found that the hydrophilicity of the carbon electrodes increased sharply by the plasma treatment: the contact angle dropped from $130^{\circ} \mathrm{C}$ for the untreated carbon to $107^{\circ} \mathrm{C}$ for the carbon treated at $50 \mathrm{~W}$. The slight decrease of contact angle with the plasma power was consistent with the increase of oxygen content with the plasma power.

Raman spectroscopy is a fast and nondestructive method for characterizing carbons [24]. Figure 5 shows the Raman spectra of the carbon materials before and after the plasma treatment. For all the known active carbon, their Raman spectra showed the common feature of two peaks ( $G$ and $D)$ in the $800-2000 \mathrm{~cm}^{-1}$ region. The $G$ and $D$ peaks lie at around 1595 and $1345 \mathrm{~cm}^{-1}$, respectively [24-33], and they are typical characteristics of graphitic carbon materials. The $G$ peak corresponds to the $\mathrm{E}_{2 \mathrm{~g}}$ phonon at the Brillouin zone center, which comes from highly ordered $\mathrm{sp}^{2}$ carbon in plane. The $\mathrm{D}$ peak is due to the breathing modes of $\mathrm{sp}^{2}$ atoms and requires a defect for its activation [25-27], which comes from finitesized crystalline $\mathrm{sp}^{2}$ carbon which possesses limited longrange order $(\mathrm{La}<1000 \AA)$. The disorder activated $\mathrm{D}$ band also exhibits a pronounced shift with laser photon energy (laser wavelength) [28]. Vidano et al. [28] reported that the position of the D band shifted from 1360 to $1330 \mathrm{~cm}^{-1}$ when the laser 


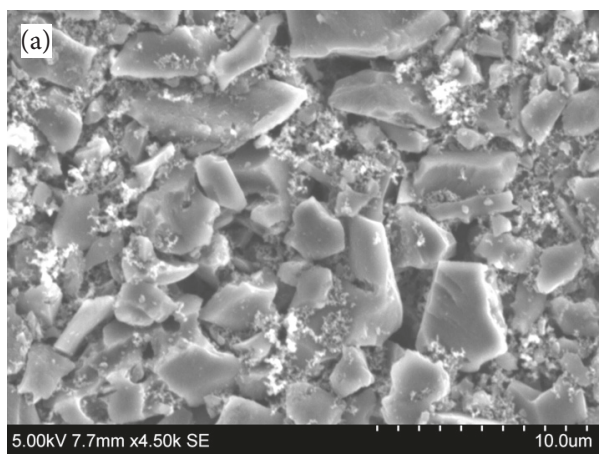

(a)

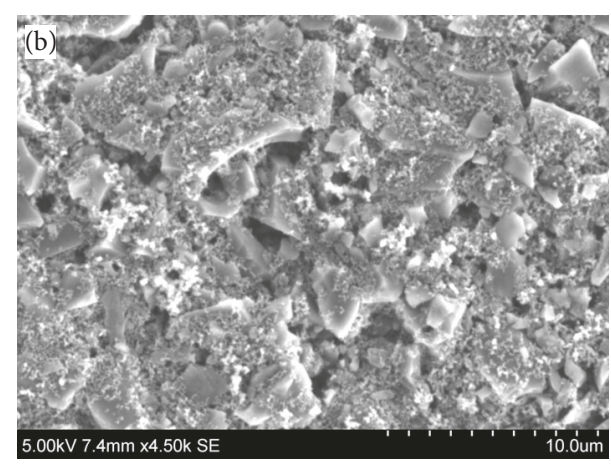

(b)

FIGURE 3: SEM images of the untreated and treated active carbon electrodes: (a) untreated and (b) plasma treated at power of 100 W.
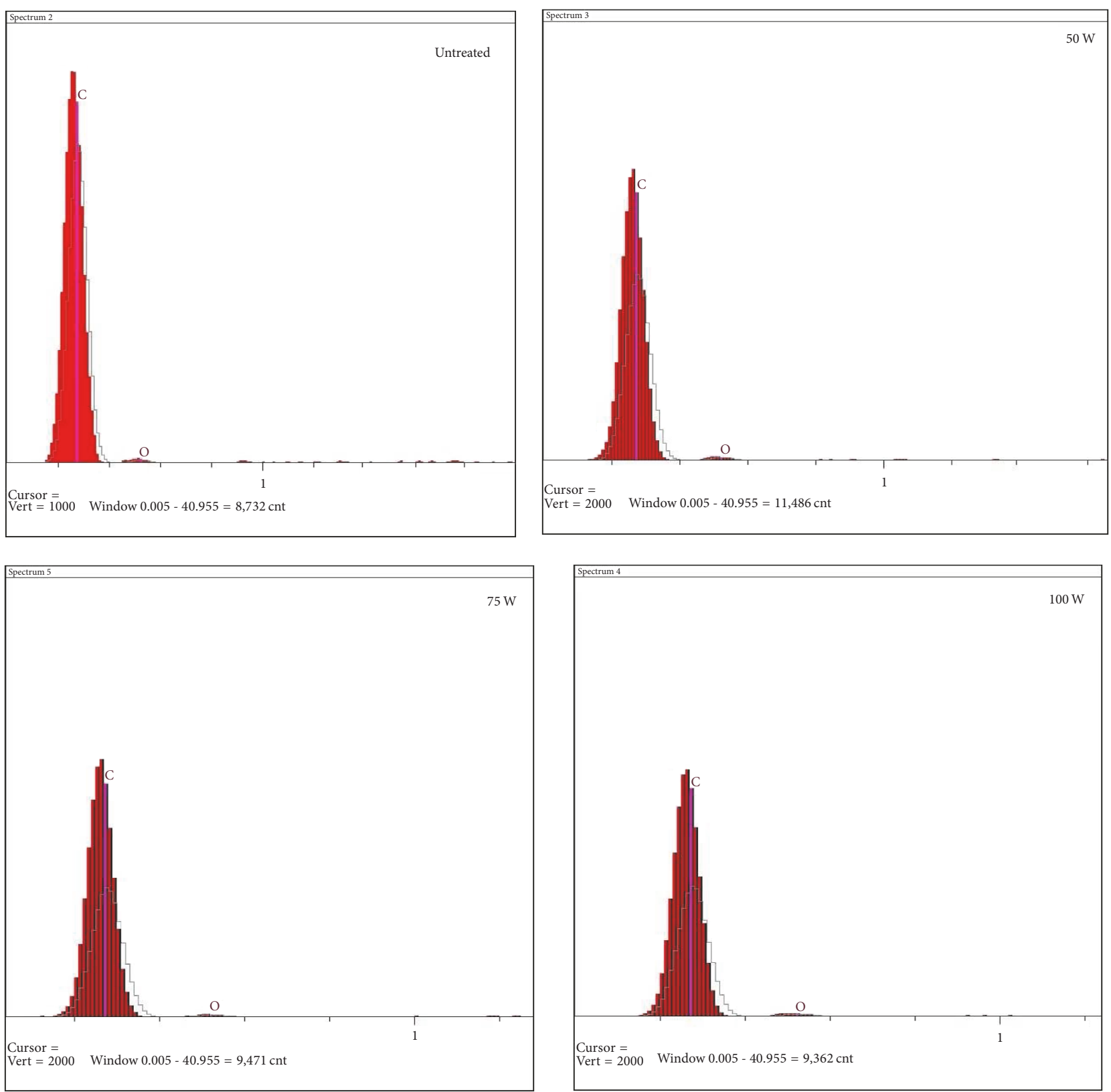

FIGURE 4: Comparison of EDX diagrams of the active carbon electrodes untreated and plasma treated at different powers: $50 \mathrm{~W}, 75 \mathrm{~W}$, and $100 \mathrm{~W}$. 
TABLE 2: Analyzed results of Raman spectra of the plasma treated carbon electrodes at different powers, comparing with the untreated electrode. FWHM is the full width at half maximum of peak.

\begin{tabular}{|c|c|c|c|c|c|c|c|}
\hline Sample & $\mathrm{D}$ band position $\left(\mathrm{cm}^{-1}\right)$ & $\mathrm{G}$ band position $\left(\mathrm{cm}^{-1}\right)$ & FWHM(D) $\left(\mathrm{cm}^{-1}\right)$ & FWHM(G) $\left(\mathrm{cm}^{-1}\right)$ & $I_{\mathrm{D}}$ & $I_{\mathrm{G}}$ & $I_{\mathrm{D}} / I_{\mathrm{G}}$ \\
\hline Untreated & 1345.4 & 1597.5 & 104.4 & 67.2 & 523.4 & 462.9 & 1.13 \\
\hline $50 \mathrm{~W}$ & 1343.3 & 1595.8 & 95.3 & 71.1 & 505.8 & 463.1 & 1.09 \\
\hline $75 \mathrm{~W}$ & 1341.5 & 1598.8 & 118.0 & 117.7 & 704.2 & 647.5 & 1.09 \\
\hline $100 \mathrm{~W}$ & 1344.7 & 1597.4 & 100.2 & 70.9 & 542.2 & 491.7 & 1.10 \\
\hline
\end{tabular}

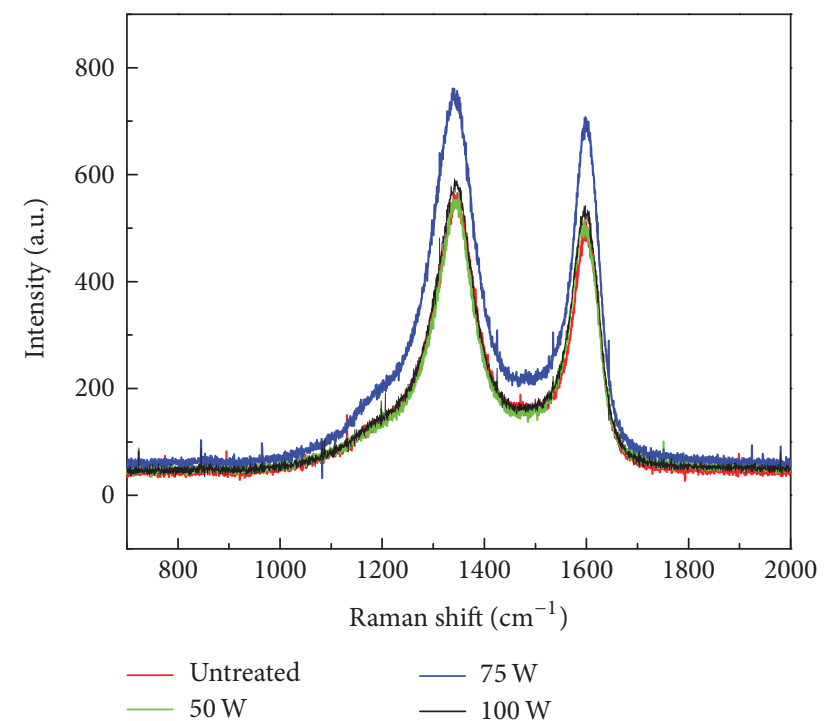

FIGURE 5: Raman shift of the untreated and plasma treated active carbon. Plasma power used was $50 \mathrm{~W}, 75 \mathrm{~W}$, and $100 \mathrm{~W}$. The G peak at $1598 \mathrm{~cm}^{-1}$ shows the highly ordered $\mathrm{sp}^{2} \mathrm{C}$ structure and its full width at half maximum (FWHM $(\mathrm{G})$ ) indicates the level of $\mathrm{sp}^{2} \mathrm{C}$ disorder. The FWHM(G) increased from $65.5 \mathrm{~cm}^{-1}$ for the untreated active carbon to $73.8 \mathrm{~cm}^{-1}$ for the $75 \mathrm{~W}$ treated. The FWHM(G) did not change much when the carbon was treated at $50 \mathrm{~W}$ and $100 \mathrm{~W}$.

wavelength increased from 488 to $647 \mathrm{~nm}$. The behavior of the $\mathrm{D}$ band for varying laser wavelength is consistent with a hypothesis that subpopulations of phonons scatter different incident photons with different wavelengths [25-27]. The G peak significantly shifts due to applied pressure and strain [28, 31].

The Raman spectra of Figure 5 are analyzed and the results are summarized in Table 2. The observed G peaks at around $1595 \mathrm{~cm}^{-1}$ shift comparing with the commonly measured frequency of $1583 \mathrm{~cm}^{-1}$ [28]. The shifts were likely due to the strain inside the carbon material. The slight shift of D band (from $1350 \mathrm{~cm}^{-1}$ to around $1345 \mathrm{~cm}^{-1}$ ) is observed. It is reported that the intensity ratio of $\mathrm{D} / \mathrm{G}$ increases with decreasing finite-crystallite size $[24,29,30]$. All the intensity ratios of $\mathrm{D} / \mathrm{G}$ of the investigated carbon materials stay around 1.10. Therefore, plasma treatment did not produce the finite crystals ( $\mathrm{La}<1000 \AA$ ); however the process broke the carbon particles into powder smaller than $1.0 \mu \mathrm{m}$. The full width at half maximum of the D peak (FWHM(D)) indicated the disorder of the finite crystals. The slight difference of FWHM(D) of $5 \mathrm{~cm}^{-1}$ before and after plasma treatment indicated small change in disorder in the finite-size scale.
The intensity of D peak weakly depended on the size of finite-sized crystals but strongly depended on the edges of the finite-sized crystals [33]. The significantly increased intensity of the $\mathrm{D}$ band at the plasma power of $75 \mathrm{~W}$ indicated that the plasma treatment produced many edges. While the edges slightly increased at $100 \mathrm{~W}$ power, they were slightly reduced at the power of $50 \mathrm{~W}$. Regarding $\mathrm{G}$ peak, the FWHM(G) slightly increased for the power at $100 \mathrm{~W}$ and decreased at $50 \mathrm{~W}$, while the FWHM $(\mathrm{G})$ jumped up at power of $75 \mathrm{~W}$ from 67.2 to $117.7 \mathrm{~cm}^{-1}$. It indicates the disorder of lattice at large scale of $\mathrm{sp}^{2}$ plane increased significantly at power of $75 \mathrm{~W}$. The disorder only increased slightly at power of $100 \mathrm{~W}$ but slightly decreased at $50 \mathrm{~W}$.

From the above discussion, it can be surmised that the RF plasma power and/or the plasma activation time had significant effects on the microstructure and morphology of the biochar. Since the time was fixed in this study, the plasma power became the main factor. At relatively low power (e.g., $50 \mathrm{~W}$ ), the plasma etching was weak and slow. Actually, a weak plasma treatment etched off some sharp edges and possibly removed some defective areas that were thin or had finite size. At high power of $100 \mathrm{~W}$, the plasma etching became so intensive that it broke the thin walls of the porous biochar. Subsequently the surface/volume ratio decreased, which led to low specific surface area. Under suitable plasma power (e.g., $\sim 75 \mathrm{~W}$ for 10 minutes), the plasma etching not only enlarged original pores, but also created new porous morphology, such as sharp edges and disordered structures in the graphitic planes which led to high functional surface area and the observed large electrosorption capacity. Similar results have been recently reported when the authors used plasma to activate biochar for supercapacitors [34]. The thermal stress produced by the plasma heating caused the carbon particles to crack apart.

3.2. Cyclic Voltammograms. The cyclic voltammograms of plasma treated AC electrodes in $0.5 \mathrm{M} \mathrm{NaCl}$ solution at scan rate of $0.015 \mathrm{~V} / \mathrm{s}$ are displayed in Figure 6 and compared with that of the untreated carbon electrode. The accumulation of charge at the electric double layer when ions were adsorbed was responsible for the typical box-shape hysteresis. Otherwise, pseudo-faradic reactions could not be ignored as revealed by the occurrence of sharply increased anodic current at potentials above $+1.0 \mathrm{~V}$ and of cathodic current feature at potential more negative than $-0.3 \mathrm{~V}$. The value of specific capacitance at $0.25 \mathrm{~V}$, where there was no obvious faradic current observed, was calculated according to

$$
C=\frac{i}{v}
$$




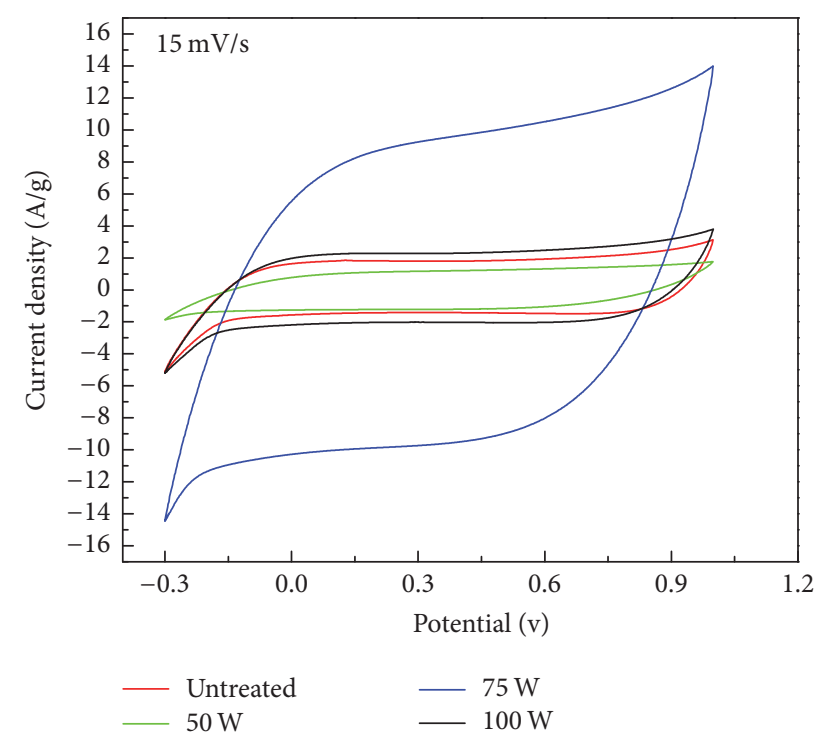

FIGURE 6: Comparison of cyclic voltammograms in $0.5 \mathrm{M} \mathrm{NaCl}$ for the untreated active carbon electrodes and the treated electrodes at different plasma power of $50 \mathrm{~W}, 75 \mathrm{~W}$, and $100 \mathrm{~W}$. From the CV curves, the capacitance at $0.25 \mathrm{~V}$ was calculated to be $120.32 \mathrm{~F} / \mathrm{g}$, $76.03 \mathrm{~F} / \mathrm{g}, 599.89 \mathrm{~F} / \mathrm{g}$, and $151.70 \mathrm{~F} / \mathrm{g}$ for the electrodes of untreated and treated at $50 \mathrm{~W}, 75 \mathrm{~W}$, and $100 \mathrm{~W}$, respectively.

where $C$ was the capacitance of double layer $(\mathrm{F} / \mathrm{g}), i$ was the forward current at $0.25 \mathrm{~V}(\mathrm{~A} / \mathrm{g})$, and $v$ was potential scan rate $(\mathrm{V} / \mathrm{s})$.

From the above equation, the corresponding values of specific capacitance were calculated to be $76.0 \mathrm{~F} / \mathrm{g}, 599.9 \mathrm{~F} / \mathrm{g}$, and $151.7 \mathrm{~F} / \mathrm{g}$ for the carbon electrodes treated at powers of $50 \mathrm{~W}, 75 \mathrm{~W}$, and $100 \mathrm{~W}$, with the comparison of $120.3 \mathrm{~F} / \mathrm{g}$ for the untreated carbon electrode. The capacitance increased fourfold at the plasma power of $75 \mathrm{~W}$ and decreased slightly at the plasma power of $50 \mathrm{~W}$ and increased slightly at the plasma power of $100 \mathrm{~W}$. The most precise technique for the measurement of electrochemical double layer capacitance, electrochemical impedance spectroscopy (EIS), was also employed to investigate these electrodes. The respective values of $69.5 \mathrm{~F} / \mathrm{g}, 214.0 \mathrm{~F} / \mathrm{g}$, and $98.7 \mathrm{~F} / \mathrm{g}$ were for the electrodes treated at $50 \mathrm{~W}, 75 \mathrm{~W}$, and $100 \mathrm{~W}$ and the value $75.2 \mathrm{~F} / \mathrm{g}$ was for the untreated ones. The presence of faradaic currents at these electrodes deformed the cyclic voltammograms and caused measurement errors. The applying potential during cyclic voltammetry on the carbon electrode treated at $75 \mathrm{~W}$ could activate the carbon material further because of breaking graphite planes at defects produced by plasma treatment at $75 \mathrm{~W}$. The above two factors were supposed to lead to the astonishing large values of $599.9 \mathrm{~F} / \mathrm{g}$ by a single slow cyclic voltammetry scan at $15 \mathrm{mV} / \mathrm{s}$. The EIS measurement and discussion were presented elsewhere in detail.

The change of capacitance was consistent with the edge amount of the planar graphitic carbon analyzed from Raman spectra. The vertical face of planar $\mathrm{sp}^{2}$ carbon was chemically inert and had low double layer capacitance [35]. Therefore, the largest capacitance could be strongly attributed to the highest edges of the treated active carbon at $75 \mathrm{~W}$ plasma power and slightly to the disorder of $\mathrm{sp}^{2}$ carbon in large scale and finite size. C-O groups in carbon materials could make the carbon surface hydrophilic and increase the double layer capacitance. The oxygen content increased after the plasma treatment and the contact angle was observed to drop sharply after plasma treatment. Therefore, the $\mathrm{C}-\mathrm{O}$ groups produced by the plasma treatment contributed to the capacitance significantly, while the small changes in oxygen content and in contact angle among the electrodes treated by different plasma power were observed, so that the changes in material structure mainly caused the difference in the capacitance for the electrodes treated at different powers.

3.3. Electrosorption. The AC electrode pairs were used for electrosorption and desorption cyclic tests and an example is illustrated in Figure 7. In the cycle, an adsorption (charging) process included a voltage drop of $1.5 \mathrm{~V}$ applied with an electrode pair over five hours followed by a reverse desorption (discharging) process of removing the applied voltage. The corresponding current indicated the charging process when the voltage of $1.5 \mathrm{~W}$ was applied and the discharging process when the potential dropped to zero. The stable current at the charging process indicated the faradic current at the applied voltage which was $7.46 \times 10^{-5} \mathrm{~A}$, while the current dropped to zero at the stable stage in the relaxation process. In the charging process, the solution conductivity dropped from 14.0 to $8.9 \mu \mathrm{S} / \mathrm{cm}$ in $10,000 \mathrm{~s}$. This fact corresponded to the concentration dropping from 0.100 to $0.065 \mathrm{mM}$. In the relaxation process, it took $5 \mathrm{~h}$ for the absorbed ions to be released back to the water. In the cycles, the solution $\mathrm{pH}$ was kept stable at 6.8 .

The electrosorption capacity $(\mathrm{mg} / \mathrm{g})$ of all the carbon electrodes is presented in Figure 8. It was found that all the carbon electrodes were saturated with salt in $10000 \mathrm{~s}$. The saturated capacities were $0.11 \mathrm{mg} / \mathrm{g}, 6.15 \mathrm{mg} / \mathrm{g}$, and $2.10 \mathrm{mg} / \mathrm{g}$, respectively, for the $\mathrm{AC}$ treated at $50 \mathrm{~W}, 75 \mathrm{~W}$, and $100 \mathrm{~W}$, comparing with $1.01 \mathrm{mg} / \mathrm{g}$ for the untreated ones. The $75 \mathrm{~W}$ plasma treating led to 5.1 times increase in the absorption capacity. The capacity change with the plasma power was consistent with the discussion of $\mathrm{sp}^{2}$ carbon edges in finite scale and disorders in large scale from the Raman spectra.

\section{Conclusion}

Plasma treatment by a capacitively coupled plasma source has been first studied to activate commercial active carbon for deionization. An optimized plasma power exists for the treatment to increase electrosorption capacity when the plasma power ranges from $50 \mathrm{~W}$ to $100 \mathrm{~W}$. The maximum of electrosorption capacity of $\mathrm{NaCl}$ salt happens at the plasma power of $75 \mathrm{~W}$. The electrosorption capacity increases 5.1-fold after the plasma treatment at $75 \mathrm{~W}$ in comparison with the capacity of the untreated carbon electrode pair. The microRaman spectra indicate that the $\mathrm{sp}^{2}$ carbon edges of the finitesized crystals (smaller than $1000 \AA$ ) and disorder in the large lattice of $\mathrm{sp}^{2}$ carbon have largely increased after the plasma treatment at a power of $75 \mathrm{~W}$. It has also been observed that the largest capacitance of electrical double layer in $0.5 \mathrm{M}$ $\mathrm{NaCl}$ occurs for the carbon treated at the plasma power of 


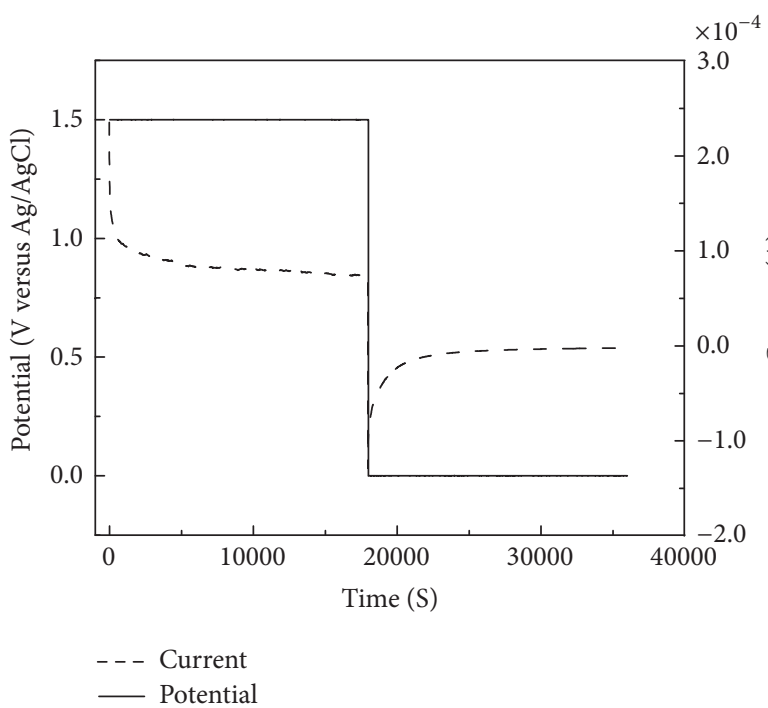

(a)

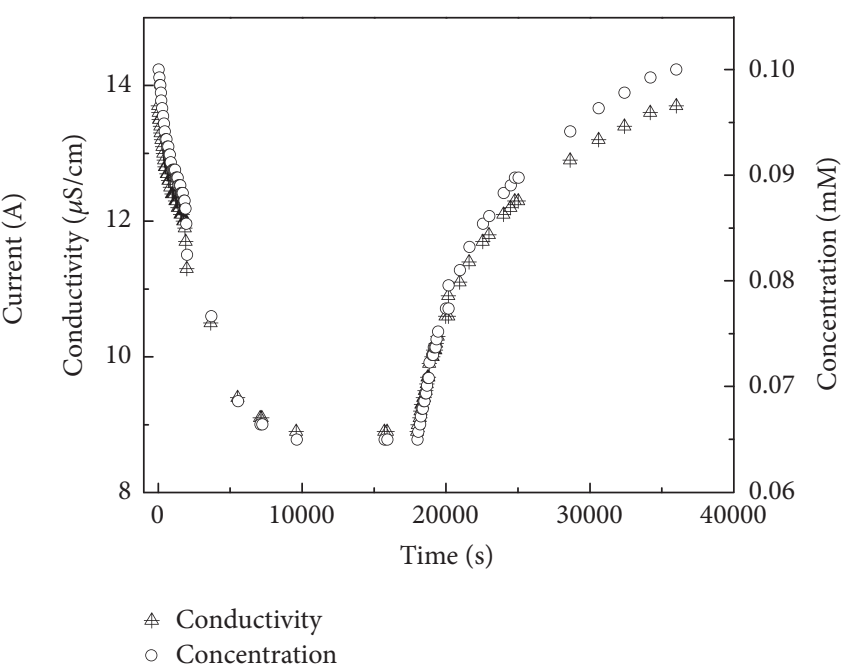

(b)

Figure 7: (a) The applied potential with time on the couple electrodes of the active carbon treated at plasma power of $100 \mathrm{~W}$ and the response of current with time. (b) The change of conductivity with time and its corresponding concentration for the solution during the electrosorption with the couple electrodes of the carbon treated at plasma power of $100 \mathrm{~W}$.

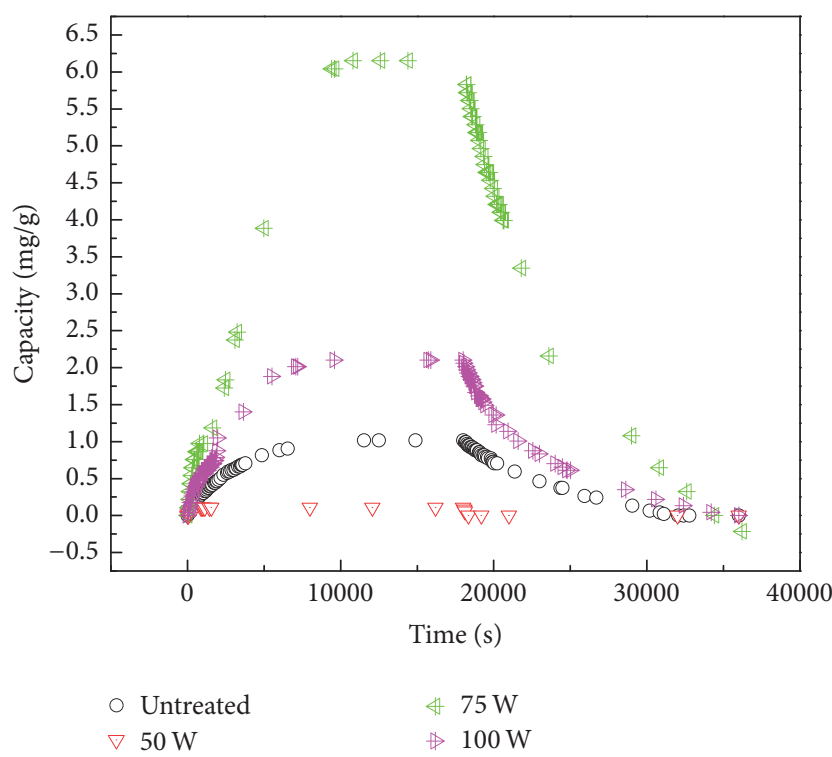

FIGURE 8: The capacities of electrosorption for the coupled electrodes of active carbon treated at different plasma powers $(50 \mathrm{~W}$, $75 \mathrm{~W}$, and $100 \mathrm{~W}$ ), compared with untreated carbon electrodes.

$75 \mathrm{~W}$. The increased $\mathrm{sp}^{2}$ carbon edges and lattice disorder by plasma etching would contribute to the capacity increase. More detailed research is under way.

\section{Disclosure}

An earlier version of this work was presented as a poster at the 7th International Conference on Advanced Nanomaterials 2016 in Portugal.

\section{Conflicts of Interest}

The authors declare that there are no conflicts of interest regarding the publication of this paper.

\section{Acknowledgments}

This research was supported by NSF Award nos. 1462389 and 1536209 and North Central Regional Sun Grant Center at South Dakota State University through a grant provided by the US Department of Energy Bioenergy Technologies Office under Award no. DE-FG36-08GO88073. The work was also supported by the Michigan Economic Development Corporation MTRAC Program: Grant CASE 179448 of the 21st Century Jobs Trust Fund received through the Michigan Strategic Fund from the State of Michigan. A. Zeng is grateful for the FCT-Portuguese Postdoctoral Fellowships provided by Portuguese Government (SFRH/BPD/81990/2011). A. Zeng, V. F. Neto, and B. Gabriel acknowledge FCT Grant UID/EMS/00481/2013.

\section{References}

[1] C. J. Gabelich, T. D. Tran, and I. H. Suffet, "Electrosorption of inorganic salts from aqueous solution using carbon aerogels," Environmental Science and Technology, vol. 36, no. 13, pp. 30103019, 2002.

[2] T. Humplik, J. Lee, S. C. O'Hern et al., "Nanostructured materials for water desalination," Nanotechnology, vol. 22, no. 29, Article ID 292001, 2011.

[3] M. A. Anderson, A. L. Cudero, and J. Palma, "Capacitive deionization as an electrochemical means of saving energy and delivering clean water. Comparison to present desalination practices: Will it compete?" Electrochimica Acta, vol. 55, no. 12, pp. 3845-3856, 2010. 
[4] Y. Liu, L. Pan, X. Xu, T. Lu, Z. Sun, and D. H. C. Chua, "Enhanced desalination efficiency in modified membrane capacitive deionization by introducing ion-exchange polymers in carbon nanotubes electrodes," Electrochimica Acta, vol. 130, pp. 619-624, 2014.

[5] Z. Sui, Q. Meng, X. Zhang, R. Ma, and B. Cao, "Green synthesis of carbon nanotube-graphene hybrid aerogels and their use as versatile agents for water purification," Journal of Materials Chemistry, vol. 22, no. 18, pp. 8767-8771, 2012.

[6] Y. Zhao, Y. Wang, R. Wang, Y. Wu, S. Xu, and J. Wang, "Performance comparison and energy consumption analysis of capacitive deionization and membrane capacitive deionization processes," Desalination, vol. 324, pp. 127-133, 2013.

[7] Y. Bouhadana, E. Avraham, M. Noked, M. Ben-Tzion, A. Soffer, and D. Aurbach, "Capacitive deionization of $\mathrm{NaCl}$ solutions at non-steady-state conditions: Inversion functionality of the carbon electrodes," Journal of Physical Chemistry C, vol. 115, no. 33, pp. 16567-16573, 2011.

[8] E. García-Quismondo, C. Santos, J. Lado, J. Palma, and M. A. Anderson, "Optimizing the energy efficiency of capacitive deionization reactors working under real-world conditions," Environmental Science and Technology, vol. 47, no. 20, pp. 1186611872, 2013.

[9] P. Hojati-Talemi, L. Zou, M. Fabretto, and R. D. Short, "Using oxygen plasma treatment to improve the performance of electrodes for capacitive water deionization," Electrochimica Acta, vol. 106, pp. 494-499, 2013.

[10] C. Yan, L. Zou, and R. Short, "Polyaniline-modified activated carbon electrodes for capacitive deionisation," Desalination, vol. 333, no. 1, pp. 101-106, 2014.

[11] G. Wang, B. Qian, Q. Dong, J. Yang, Z. Zhao, and J. Qiu, "Highly mesoporous activated carbon electrode for capacitive deionization," Separation and Purification Technology, vol. 103, pp. 216-221, 2013.

[12] J.-H. Choi, "Fabrication of a carbon electrode using activated carbon powder and application to the capacitive deionization process," Separation and Purification Technology, vol. 70, no. 3, pp. 362-366, 2010.

[13] I. Villar, S. Roldan, V. Ruiz et al., "Capacitive deionization of $\mathrm{NaCl}$ solutions with modified activated carbon electrodes," Energy and Fuels, vol. 24, no. 6, pp. 3329-3333, 2010.

[14] M. C. Zafra, P. Lavela, G. Rasines, C. Macías, J. L. Tirado, and C. O. Ania, "A novel method for metal oxide deposition on carbon aerogels with potential application in capacitive deionization of saline water," Electrochimica Acta, vol. 135, pp. 208-216, 2014.

[15] H.-H. Jung, S.-W. Hwang, S.-H. Hyun, K.-H. Lee, and G.-T. Kim, "Capacitive deionization characteristics of nanostructured carbon aerogel electrodes synthesized via ambient drying," Desalination, vol. 216, no. 1-3, pp. 377-385, 2007.

[16] G. Wang, C. Pan, L. Wang et al., "Activated carbon nanofiber webs made by electrospinning for capacitive deionization," Electrochimica Acta, vol. 69, pp. 65-70, 2012.

[17] G. Wang, Q. Dong, Z. Ling, C. Pan, C. Yu, and J. Qiu, "Hierarchical activated carbon nanofiber webs with tuned structure fabricated by electrospinning for capacitive deionization," Journal of Materials Chemistry, vol. 22, no. 41, pp. 21819-21823, 2012.

[18] C. Nie, L. Pan, Y. Liu et al., "Electrophoretic deposition of carbon nanotubes-polyacrylic acid composite film electrode for capacitive deionization," Electrochimica Acta, vol. 66, pp. 106109, 2012.

[19] L. Wang, M. Wang, Z.-H. Huang et al., "Capacitive deionization of $\mathrm{NaCl}$ solutions using carbon nanotube sponge electrodes,"
Journal of Materials Chemistry, vol. 21, no. 45, pp. 18295-18299, 2011.

[20] C. Tsouris, R. Mayes, J. Kiggans et al., "Mesoporous carbon for capacitive deionization of saline water," Environmental Science and Technology, vol. 45, no. 23, pp. 10243-10249, 2011.

[21] D. Zhang, X. Wen, L. Shi, T. Yan, and J. Zhang, "Enhanced capacitive deionization of graphene/mesoporous carbon composites," Nanoscale, vol. 4, no. 17, pp. 5440-5446, 2012.

[22] J.-A. Kim, I.-S. Park, J.-H. Seo, and J.-J. Lee, "A development of high power activated carbon using the $\mathrm{KOH}$ activation of soft carbon series cokes," Transactions on Electrical and Electronic Materials, vol. 15, no. 2, pp. 81-86, 2014.

[23] J. Jiang, L. Zhang, X. Wang et al., "Highly ordered macroporous woody biochar with ultra-high carbon content as supercapacitor electrodes," Electrochimica Acta, vol. 113, pp. 481-489, 2013.

[24] A. C. Ferrari and J. Robertson, "Raman spectroscopy in carbons: from nanotubes to diamond, Theme Issue," Philosophical Transactions of The Royal Society A, vol. 362, pp. 2267-2565, 2004.

[25] F. Tuinstra and J. L. Koenig, "Raman spectrum of graphite," Journal of Chemical Physics, vol. 53, no. 3, 1126 pages, 1970.

[26] A. C. Ferrari and J. Robertson, "Interpretation of Raman spectra of disordered and amorphous carbon," Physical Review B: Condensed Matter and Materials Physics, vol. 61, no. 20, 14095 pages, 2000.

[27] C. Thomsen and S. Reich, "Double resonant Raman scattering in graphite," Physical Review Letters, vol. 85, no. 24, 5214 pages, 2000.

[28] R. P. Vidano, D. B. Fischbach, L. J. Willis, and T. M. Loehr, "Observation of Raman band shifting with excitation wavelength for carbons and graphites," Solid State Communications, vol. 39, no. 2, pp. 341-344, 1981.

[29] A. V. Baranov, A. N. Bekhterev, Y. S. Bobovich, and V. I. Petrov, "Interpretation of some singularities in Raman spectra of graphite and glass carbon," Optics and Spectroscopy, vol. 62, 1036 pages, 1987.

[30] T. P. Mernagh, R. P. Cooney, and R. A. Johnson, "Raman spectra of Graphon carbon black," Carbon, vol. 22, no. 1, pp. 39-42, 1984.

[31] O. Frank, G. Tsoukleri, I. Riaz et al., "Development of a universal stress sensor for graphene and carbon fibres," Nature Communications, vol. 2, no. 1, article no. 255, 2011.

[32] S. Reich and C. Thomsen, "Raman spectroscopy of graphite," Philosophical Transactions of the Royal Society A: Mathematical, Physical and Engineering Sciences, vol. 362, pp. 2271-2288, 2004.

[33] G. Katagiri, H. Ishida, and A. Ishitani, "Raman spectra of graphite edge planes," Carbon, vol. 26, no. 4, pp. 565-571, 1988.

[34] R. K. Gupta, M. Dubey, P. Kharel, Z. Gu, and Q. H. Fan, "Biochar nanomaterials activated by oxygen plasma for supercapacitors," Journal of Power Sources, vol. 274, 1300 pages, 2015.

[35] P. Los, A. Lasia, J. Fournier, H. Ménard, and L. Brossard, "AC Impedance Studies of Highly Oriented Pyrolytic Graphite in $1 \mathrm{M}$ $\mathrm{NaOH}$ Solution," Journal of the Electrochemical Society, vol. 141, no. 10, pp. 2716-2721, 1994. 

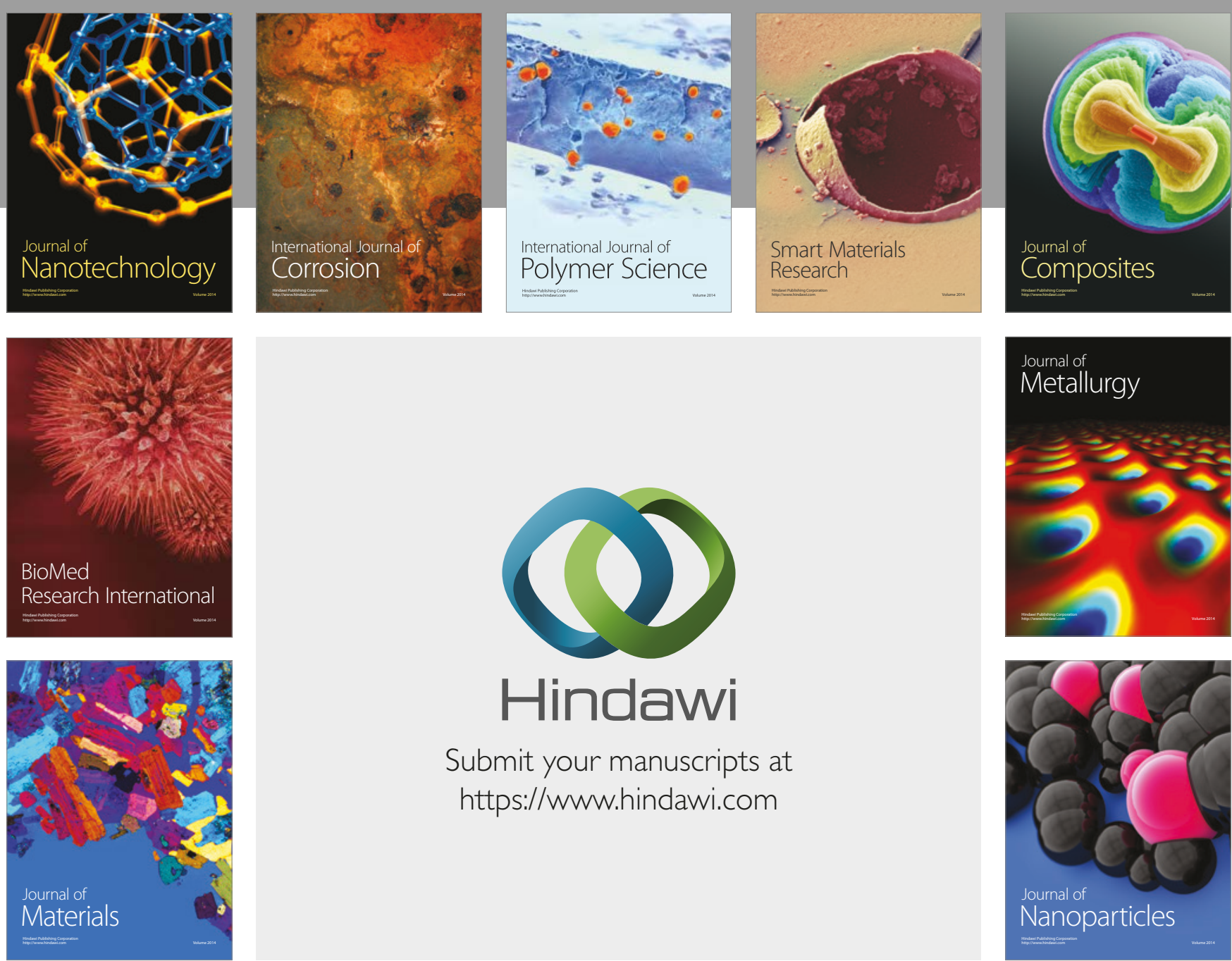

\section{Hindawi}

Submit your manuscripts at

https://www.hindawi.com
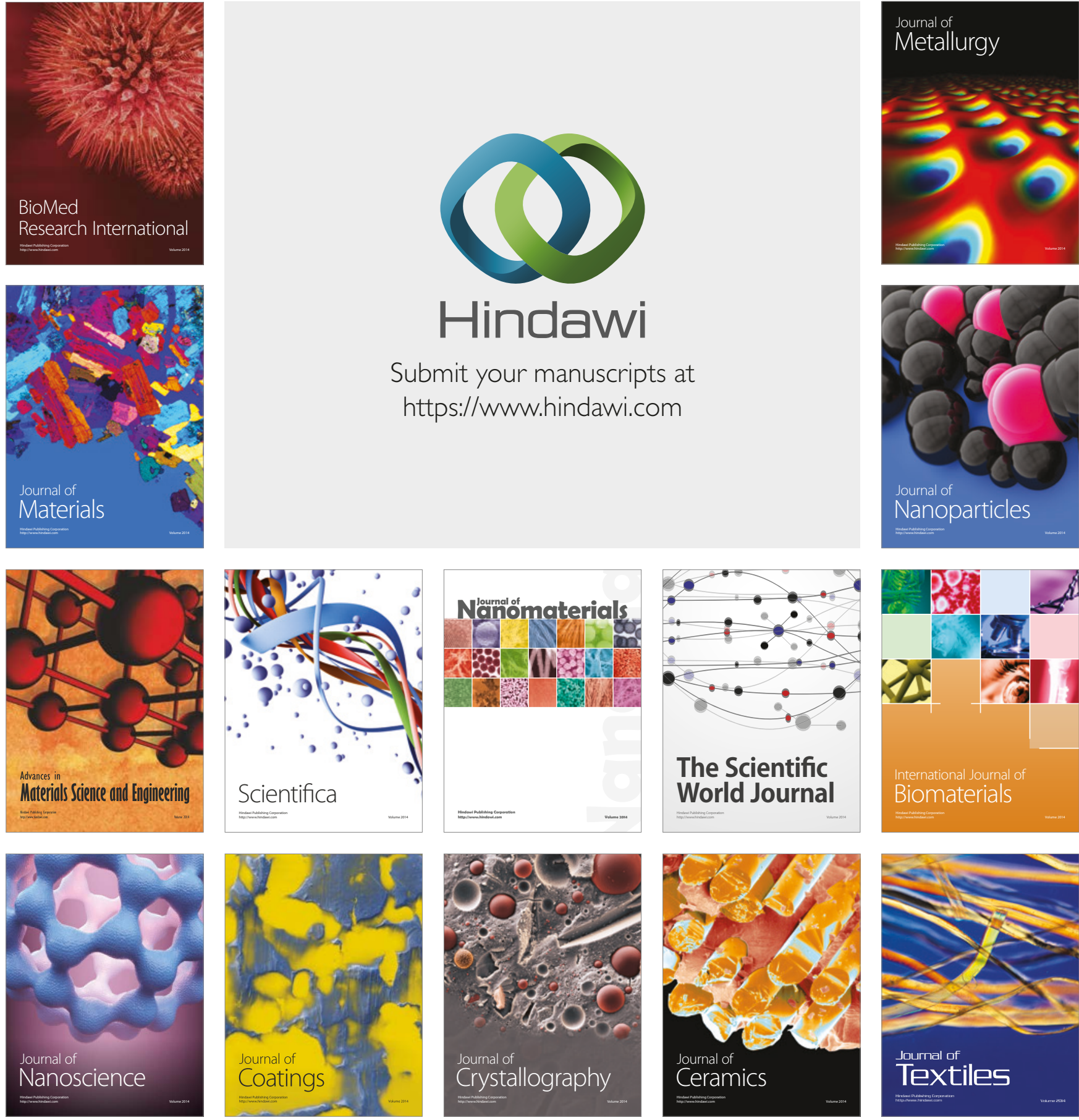

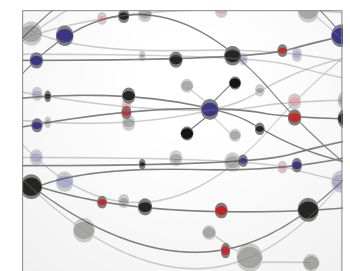

The Scientific World Journal
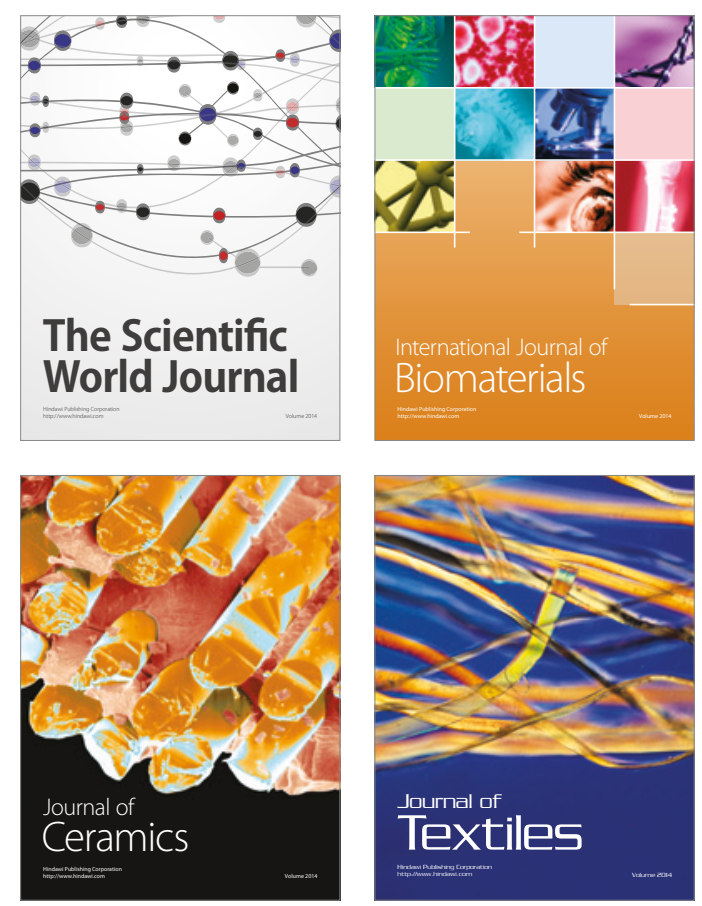